\title{
Medical Students-How Much Science Education Is Needed?
}

\author{
D. J. Wilson ${ }^{1}$ • B. H. L. Harris ${ }^{1}$ - S. J. Hibbitts ${ }^{1}$ - S. Riley ${ }^{1}$
}

Published online: 22 April 2016

(C) International Association of Medical Science Educators 2016

During a discussion on 'what makes a good doctor?' with new first year medical students, a patient representative said that the most important thing was that the doctor was 'knowledgeable': a sentiment with which most of us who are patients would agree. As medical science advances inexorably, the question of knowledge and particularly what scientific knowledge and to what depth it should be learnt becomes more pressing to those involved in science teaching to medical students. 'The volume of medical knowledge has exploded, the complexity of the health care system has grown, pedagogical methods have evolved, and unprecedented technological support of learners have become available' [1]. Under the heading 'becoming a physician', these authors lay out a proposal for making early year medical messages or lessons 'stick'. The example given is of first year medical students 'learning critical biochemistry pathways' using short videos and low-stakes online quizzes, with class time given over to student participative discussions

B. H. L. Harris

bhlharris@gmail.com

D. J. Wilson

WilsonDJ2@cardiff.ac.uk

S. J. Hibbitts

HibbittsSJ@cardiff.ac.uk

S. Riley

RileySG@cardiff.ac.uk

1 Centre for Medical Education, Cardiff University School of Medicine, Cardiff, Wales, UK that include the patient (a child in their example), the treating clinician and the biochemistry professor discussing a metabolic disease affecting the child. Whilst this is an interesting fliplecture construct describing how to learn, it does not state what learning is to be covered; that is the question, 'critical biochemistry pathways', is not described. Similarly, when curriculum designers consult the General Medical Council's Outcomes for graduates (Tomorrow's Doctors) [ 2], the first outcome they encounter in the section on 'the doctor as a scholar and a scientist' states that the 'graduate will be able to apply to medical practice biomedical scientific principles, method and knowledge relating to: anatomy, biochemistry, cell biology, genetics, immunology, microbiology, molecular biology, nutrition, pathology, pharmacology and physiology'. The first on the 7-item list states that the graduate will be able to 'explain normal human structure and functions'. This is paradoxical: the explicitness of learning outcomes for such extensive areas of science curriculum has little detail as compared to areas such as social sciences or clinical skills. For example, the diagnostic procedures list includes pregnancy testing, explicitly 'perform a test of the urine to detect hormones which indicate that the patient is pregnant'. Learned societies both in the UK and USA have produced versions of what they consider the core learning for a medical student during a medical course (Table 1). For example, the Anatomical Society of Great Britain and Ireland argued that guidance from the GMC, Medical Council of Ireland and Scottish Doctors was inadequate. The Society derived a core syllabus of 182 learning outcomes in anatomy at a level regarded to be the minimum expected of a recentlyqualified medical graduate in the UK and Ireland. This was refined recently using a modified Delphi method [3] to 156 learning outcomes [4] using evaluation by 39 experts, 
Table 1 Example learning outcomes from anatomy, physiology and genetics

Anatomy

Smith et al. (2016)

Physiology

Carroll RG, Navar LG,

Blaustein MP

(2012)

\footnotetext{
Genetics

http://www.

geneticseducation.

nhs.uk/downloads/

0047Learning

Outcomes in

Genetics for

Medical_Students.

pdf
}

Describe and demonstrate the Describe and demonstrate the Final learning outcome: main anatomical landmarks of the clavicle, scapula, humerus, radius and ulna. Recognise the bones of the wrist and hand and their relative positions. Identify those bones that are commonly damaged (scaphoid and lunate) and predict functional impairment following such damage

List four causes of edema and Author: Disruption of the describe how each results from the disruption of the balance of microcirculatory fluid exchange and lymph flow

Describe how the theory of metabolic regulation of blood flow accounts for the observed phenomena of autoregulation, active hyperemia and reactive hyperemia

\section{Understand the use of polymorphisms as genetic markers}

main palpable anatomical landmarks of the clavicle, scapula, humerus, radius and ulna. Identify the bones of the wrist and hand and their relative positions. Identify those bones that are commonly injured e.g. scaphoid and predict functional impairment

\section{Starling forces,} permeability or lymphatic drainage each can cause edema

Author: Three theories can account for autoregulation. I feel that understanding of the metabolic theory has the most practical advantages, and I want to focus the student's attention on that area

'Understand' is not a useful verb in this context
Describe and demonstrate the main palpable anatomical landmarks of the clavicle, scapula, humerus, radius and ulna. Identify the bones of the wrist and hand and their relative positions. Identify those bones that are commonly injured e.g. scaphoid

Committee: 'OK as written (a minor miracle)'
Committee: 'OK as written (they must have gotten tired)'

\section{Suggest: Demonstrate how polymorphisms can be used as genetic markers}

Delphi stages 1 and 2 identified parts of the original learning outcomes that were not relevant and required modification or contextualisation. Consensus: 26 accepted the revised outcome, one rejected it

The anatomical example shows the evolution of a learning outcome using a modified Delphi method, the two physiological examples illustrate committee decisions on learning outcomes and the genetics example shows the need to refine published learning outcomes to get precision in descriptors

including clinicians. Similarly, the American Physiological Society and the Association of Chairs of Departments of Physiology co-authored 860 medical physiology learning objectives, using the rationale that the learning objectives were 'the foundations needed for further studies in pharmacology, pathology, pathophysiology, and medicine' [5]. The NHS National Genetics and Genomics Education Centre, lists 33 learning outcomes in genetics and genomics for medical students [6], and although some are clear and topical, such as describing the contribution of mitochondrial DNA and how it is transmitted, other outcomes are not really helpful, as the verbs used are vague and thus difficult to assess. Such documents undergo revisions, and getting a consensus view of what should be contained in a core curriculum is not straightforward. In addition, learning outcomes may lead with 'understand' or 'to be aware of' and lack specific examples. In these instances, it is difficult for the learner to know what level of 'understanding' or 'awareness' they must reach. To deal with this concern, the learners need to understand the medical context of their learning. Scientific stories linking the science to clinically relevant situations has been argued to be the most effective way $[7,8]$ and this links with medical curricular shift towards casebased learning [9].

Science education in the medical curriculum, whether derived from either a top-down (i.e. expert-led) or a bottom-up (student and teacher-led) approach [10], is problematic in that curriculum designers are confronted with the dilemma of everincreasing pressure on curricular time. It is challenging to include the most up-to-date medical science, whilst ensuring that there is sufficient stimulus for students to learn other important clinical and doctoring skills. According to one report, there have been around 50 topics, disciplines and skills advocated for inclusion in the medical curriculum from the education literature [11] in the period 2005-2011, including leadership, multiculturalism, communication skills and complementary/alternative medicine.

The solution, in part, may be to encourage medical education to move away from fostering the traditional educational 
institution 'just-in-case learning' to 'just-in-time learning' [12]. This can be paralleled to the change that has taken place in the acquisitions policies of libraries: moving away from 'possible use' towards 'immediate need' and purchase only what is needed, thereby allowing libraries to spend their funds more effectively.

Just-in-time learning exploits the rapid advances in technology, particularly the increasing speed and ease of access that makes up-to date, evidence-based electronic resources such as the National Institute for Health and Care Excellence Clinical Knowledge Summaries and Map of Medicine available to medical students at all levels. Unsurprisingly, medical students have an appetite for such rapidly accessible and reliable information, but it is important that they are educated about the potential pitfalls of using resources that are poorly evidence-based [13]. Student's ability to judge the reliability of sources and an understanding of the hierarchy of evidence should be developed early in the medical course. Students need to understand the scientific method, that there is a probationary period with all published evidence and that facts are mutable. In short, they should develop critical appraisal skills. Allied to this is the desire to make medical student learning affective [14].

As continuing medical education and revalidation becomes the norm for medical practitioners, it seems important that the educational model developed within medical students is one of learning to promote continual professional development, rather than for simply passing exams. Students that embark on this model of learning will find it challenging compared to previous educational systems where they excelled and which are largely based on rewarding performance in examinations, morselised and modularised content and explicit examination criteria. Such students require science learning to be contextualised, with the patient at the centre. But one must remember medicine without science is static; the concepts of science and the scientific method are the ways in which medicine advances.

\section{Authors' Contributions}

Professor D. J. Wilson.

1. Professor D. J. Wilson conceived the idea of the article and then discussed it with the other authors.

2. Professor D. J. Wilson jointly wrote the initial draft of the article and produced the 4th, 5th and final drafts. Professor D. J. Wilson critically reviewed the 2 nd and 3 rd drafts making comments and changes where appropriate.

3. Professor D. J. Wilson has approved the final draft for submission and potential publication.

4. Professor D. J. Wilson agrees to be accountable for all aspects of the work and agrees to investigate and resolve any questions relating to the accuracy or integrity of the work.

\section{Dr. BHL Harris.}

1. Benjamin Harris was consulted in the early stages about the possibility of writing the manuscript. He discussed ideas with Prof. Wilson which were incorporated into the drafts and final manuscript.

2. Benjamin Harris was consulted on the initial draft of the article and produced thee $3 \mathrm{rd}$, 5th and final drafts. Benjamin Harris critically reviewed the all drafts making comments and changes where appropriate.
3. Benjamin Harris has approved the final draft for submission and potential publication.

4. Benjamin Harris agrees to be accountable for all aspects of the work and agrees to investigate and resolve any questions relating to the accuracy or integrity of the work.

\section{Dr. S. J. Hibbitts.}

1. Sam Hibbitts was consulted in the early stages about the possibility of writing the manuscript. She discussed ideas with Prof. Wilson which were incorporated into the drafts and final manuscript.

2. Sam Hibbitts critically reviewed the $1 \mathrm{st}, 3 \mathrm{rd}$, 4th and 5 th drafts making comments and changes where appropriate.

3. Sam Hibbitts has approved the final draft for submission and potential publication.

4. Sam Hibbitts agrees to be accountable for all aspects of the work and agrees to investigate and resolve any questions relating to the accuracy or integrity of the work.

Dr. S. Riley.

1. Steve Riley was consulted in the early stages about the possibility of writing the manuscript. He discussed ideas with Prof. Wilson which were incorporated into the drafts and final manuscript.

2. Steve Riley produced the $2 \mathrm{nd}$ draft and critically reviewed all drafts making comments and changes where appropriate.

3. Steve Riley has approved the final draft for submission and potential publication.

4. Steve Riley agrees to be accountable for all aspects of the work and agrees to investigate and resolve any questions relating to the accuracy or integrity of the work.

\section{References}

1. Prober CG, Heath C. Lecture halls without lectures - a proposal for medical education. N Engl J Med. 2012;366:1657-9.

2. General Medical Council. Outcomes for graduates (Tomorrows Doctors). London. 2015. [Accessed: 20/12/15] http://www.gmcuk.org/Outcomes_for_graduates_Jul_15.pdf_61408029.pdf

3. Smith CF, Finn GM, Stewart J, et al. The Anatomical Society core regional anatomy for undergraduate medicine. J Anat. 2016;228: $15-23$.

4. Smith CF, Finn GM, Stewart J, et al. Anatomical Society core regional anatomy for undergraduate medicine: the Delphi process. J Anat. 2016;228:2-14.

5. Carroll RG, Navar LG \& Blaustein MP. Medical physiology learning objectives. American Physiological Society Education, Publication Number 2012-01, 2012

6. National Genetics and Genomics Education Centre. Learning outcomes in genetics and genomics for medical students. London. 2014 [Accessed: 21/12/15] http://www.geneticseducation.nhs.uk/ downloads/Learnng_Outcomes_in_Genetics_for_Medical Students 2014.pdf

7. Norman G. How basic is basic science? Adv Health Sci Educ. 2007;12:401-3.

8. Ashfar M, Han Z. Teaching and learning medical biochemistry: perspectives from a student and an educator. Med Sci Educ. 2014;24:339-41.

9. Srinivasan M, Wilkes M, Stevenson F, Nguyen T, Slavin S. Comparing problem-based learning with case-based learning: effects of a major curricular shift at two institutions. Acad Med. 2007;82:74-82.

10. Bull S, Mattick K. What biomedical science should be included in undergraduate medical courses and how is this decided? Med Teach. 2011;32:360-7. 
11. Geraci AS, Thigpen SC. The fundamental need for relative value metrics in educational innovation. Am J Med. 2011;124:1086-9.

12. Schols M. Communities of practice: pedagogy and internet-based technologies to support educators' continuing technology professional development in higher education, International Conference of Education, Research and Innovation, Madrid, Spain, 14-16 November 2011: IATED, pp. 5276-5285.
13. Brennan N, Edwards S, Kelly N, Miller A, Harrower L, Mattick K. Qualified doctor and medical students' use of resources for accessing information: what is used and why? Health Inf Libr J. 2014;31:204-14.

14. Dornan T, Bundy C. What can experience add to early medical education? Consensus survey. Brit Med J. 2004;329:834-7. 